\title{
RETRACTED ARTICLE: Wassily Kandinsky's \\ The Yellow Sound as a total work of art
}

\author{
R. J. Cardullo ${ }^{1}$
}

Published online: 4 April 2017

(C) Akadémiai Kiadó, Budapest, Hungary 2017

Careful analysis of the recent article by Robert Cardullo, published online in Neohelicon, has led us to the conclusion that it shows extensive similarities with two earlier publications by Julia Listengarten. This makes the article an insufficiently original publication, in conflict with the publication policy of the journal Neohelicon, its publisher Akadémiai Kiadó, and Springer. For this reason the article in question has been retracted.

The Editorial Committee of Neohelicon

Electronic supplementary material The online version of this article (doi:10.1007/s11059-017-0384-y) contains supplementary material, which is available to authorized users.

R. J. Cardullo

robertcardullo@yahoo.com

1 Sorvaajankatu 3B35, 00880 Helsinki, Finland 